\title{
Importance of slat and flap devices on aircraft wings
}

\begin{abstract}
With advent of latest manufacturing processes in aviation industry, ways to improve the aerodynamic performance of aircraft wings have been researched by several companies in aviation and defence industry. These new design and manufacturing techniques help to enhance the aerodynamic behaviour of aircraft wings at high or very high Reynolds number which typically conform to the cruising altitudes of aircrafts as well as during landing and take-off stages. The slat and flap devices usually serve as extensions to main aerofoil element of an aircraft wing and intended to divert the turbulent flow along the chord length and improve the maximum lift coefficient by $40-60 \%$. More so than before, these methods have also aimed to achieve improved fuel efficiency by up to $10-13 \%$ by drag reduction. With a net change of $24 \%$ in fuel prices in aviation turbine fuel seen over the last decade, the future of commercial aviation will continue to look for advanced technologies in design of aircraft wings that are promised to provide safe and reliable air transportation.
\end{abstract}

Volume 3 Issue 2 - 2019

\author{
Vasishta Bhargava \\ GITAM University, India
}

\begin{abstract}
Correspondence: Vasishta Bhargava, Sreyas Institute of Engineering \& Technology, Hyderabad, India, Emailvasishtab@gmail.com
\end{abstract}

Received: February 07, 2019 | Published: April 22, 2019

Keywords: slat, flap, aerofoil, lift coefficient, drag coefficient

\section{Introduction}

Slats and flaps are high lift devices, intended to produce maximum lift coefficients on aerodynamically designed wings of aircraft. The use of aerodynamic extensions are done in order to increase the effective plan form area of wing thereby generating extra lift force required for an aircraft wing. A typical passenger aircraft has three stages in a flight during which the high lift devices are deployed and retracted when required. From Figure 1A, there are seven types of extensions. The first one known as plain flap is attached to trailing edge; second one is slotted flap and has cove in the aft region of main element. A split flap is integrated into the main element and activated by means of a lever near the trailing edge. A zap flap is similar to a split flap but operates using a hinged kinematic mechanism present at the main element along with a crank and lever actuator to retract and deploy when required. The most frequently used flap in aircraft is Fowler flap which forms a unique combination with main element, since it operates using a servo mechanism with a transverse beam support along the wing span. Hence to increase the lift coefficient, the no of slots can be added in order two or three and arranged in tandem at the trailing edge of aerofoil. This is done to augment maximum lift coefficient at a given angle of attack and to enable the lateral stability of aircraft during rolling manoeuvre. ${ }^{1}$

Figure 1B shows the arrangement of high lift devices on the main wing during take-off and landing stages. Figure $1 \mathrm{C}$ depicts the leading edge nose profile of a real wing mounted with slat and supported using a servo hinge for deployment. Figure 1D illustrates the fowler flap devices of a Boeing 747-400 deployed during landing. Figure 2A\&2B depicts the innovation cycle of aircraft wing design evolution over time.

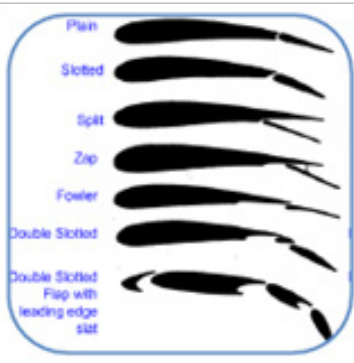

(a)

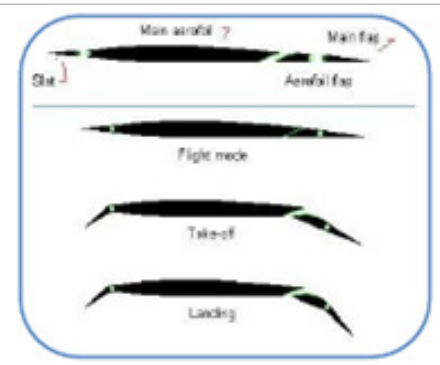

(b)

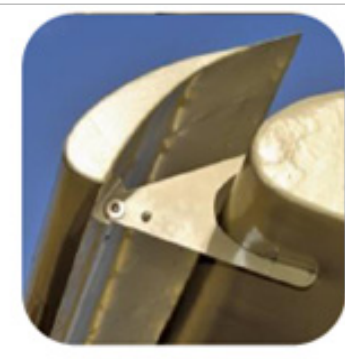

(c)

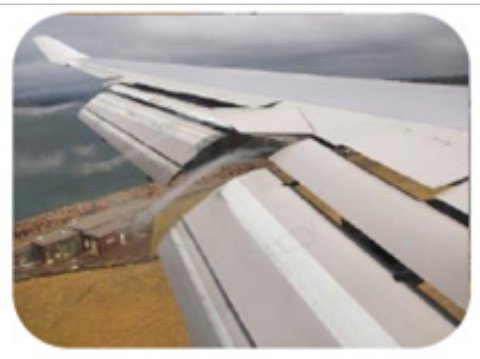

(d)

Figure I (A) Different types of flap and slat configurations on aircraft wing' (B) Position of flap and slap devices during several aircraft modes ${ }^{2}$ (C) Ventilated slat on leading edge (D) Slotted fowler flaps of Boeing 747-400 during landing.

\section{Discussion}

The aircraft wing experiences a turbulent boundary layer flow over its surface, caused due to velocity or pressure fluctuations and responsible for generation of lift. The amount of lift produced varies with geometry parameters of aerofoil and depend on three key variables viz. gap distance, ${ }^{2}$ overhang length and deflection angle ${ }^{3}$ of flap and slat devices integrated to main aerofoil. The deployment of flap and slat configurations to main aerofoil is done for the take-off stage partially since velocity of aircraft is low. The high lift and low drag action produced as result also helps to increase the pay load capacity or take-off weight of an aircraft. For smooth landing conditions the aircraft must again slow before the touch down on runway for which the trailing edge flap devices are deployed to produce high lift and high drag on wing surface. This arrangement also allows the pilot to have a better visibility through nose up or nose down attitude of aircraft. The slat and flap combination produces a mechanism which effectively increases the camber and total wing area distributed along wing span. From Figure 3A slat contribution to lift augmentation at a given angle of attack is significant and increases the maximum $\mathrm{C}_{\mathrm{L}}$ or $\mathrm{L} / \mathrm{D}$ ratio by $10-15 \%$. Presence of leading edge slat delays the boundary layer 
flow separation and stall over main aerofoil. Further, it improves the flow control by proper mixing of mass, increase the momentum of air stream and also reduce the flow induced noise. Figure 3B shows the sectional lift coefficient comparison for plain and slotted wings. The maximum $\mathrm{C}_{\mathrm{L}}$ of 3 is obtained for wing using a fowler flap with $\sim 35 \%$ improvement.

The maximum $\mathrm{C}_{\mathrm{L}}$ obtained will also vary after long operational hours of aircraft when surface smoothness deteriorates and impacts the boundary layer transitions on wing. The take-off or landing speeds for aircraft vary between $240-300 \mathrm{~km} / \mathrm{h}$ and a function of acceleration distance on ground, climb rates with a slope angles between $2^{0}$ and $3^{0}$. The thrust to weight ratio, span wise wing loading, maximum lift coefficient, pressure and friction drag from ground rolling are other factors which affect the take-off attitude of aircraft ${ }^{4}$ In contrast the landing performance depend on additional parameter known as the approach angle. The structural load on wing during landing is kept low while it is high in cruise conditions of aircraft. Empirical studies have found that pay load capacity increase roughly an order of $15-20$ $\%$ with a change of $3 \%$ in maximum $\mathrm{C}_{\mathrm{L}}$ or glide ratio of a wing. The design process of such wings involve advanced tools like $2 \mathrm{D}$ and $3 \mathrm{D}$ CFD flow solvers to resolve the complex boundary layer flow physics. Figure 4 shows the common types of trailing edge extensions used in Boeing, Douglas and Airbus aircraft. It can be noted that no of trailing edge slots to generate maximum lift vary with aircraft manufacturer and flight range.

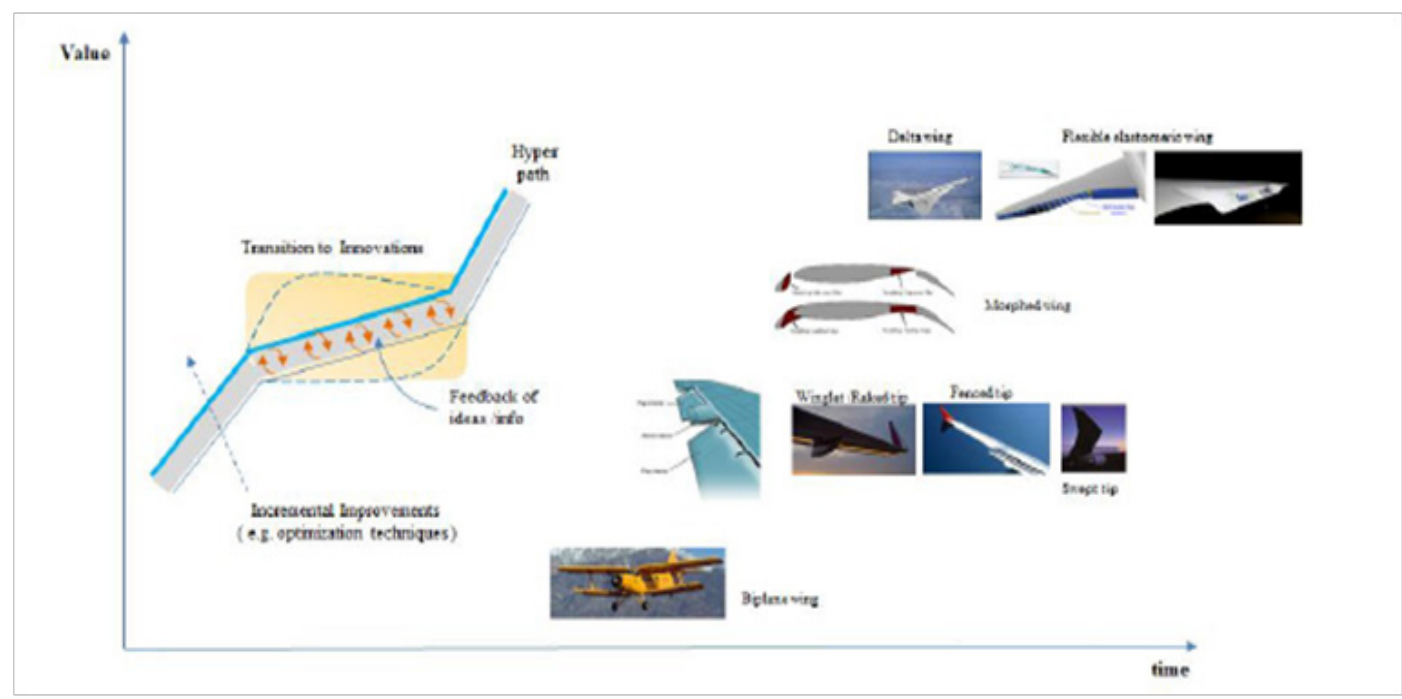

Figure 2 (A) Roadmap for innovation cycle (adapted from) ${ }^{4}$ (B) Illustration of aircraft wing innovations.
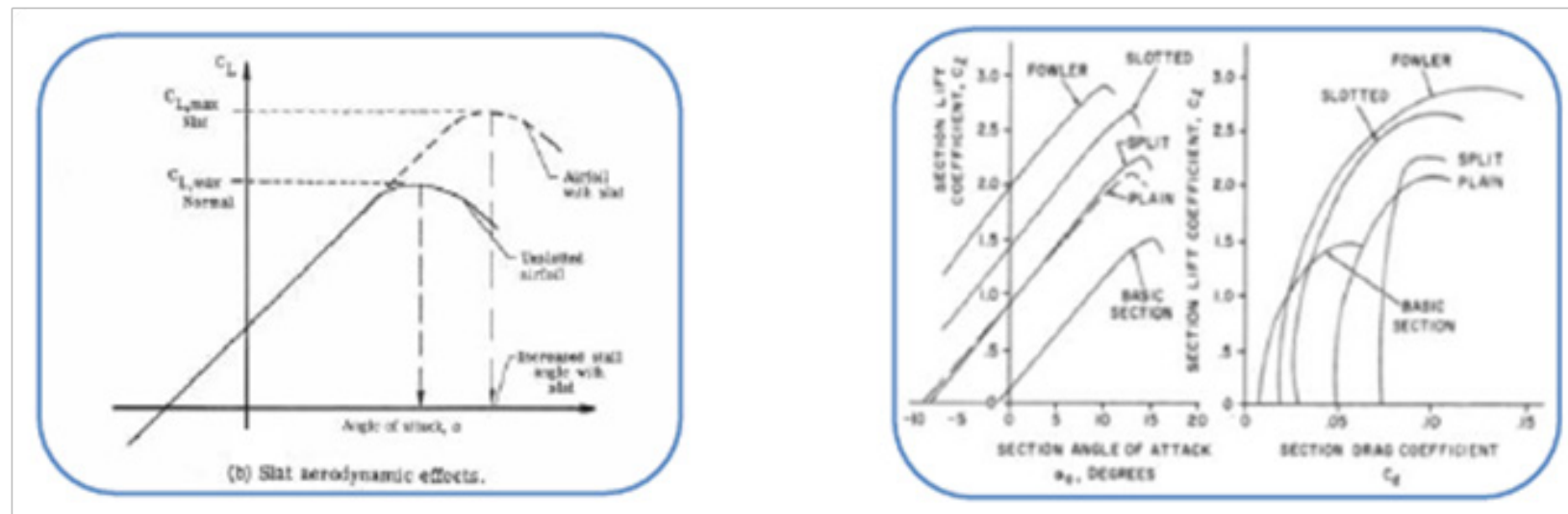

Figure 3 (A) Maximum lift coefficient, $C L$ vs angle of attack, $\alpha$ for aerofoils with slat. (B) Comparison of maximum lift coefficient, $C L$ vs angle of attack, $\alpha$, and drag polar, CL/CD for various types of flaps with respect to baseline aerofoil.

The maximum no of passengers in Boeing B-7xx series allows a gross tonnage of 560-600 tons and take--off payload between $60-80$ tons. Figure $5 \mathrm{~A}$ shows the geometry of $30 \mathrm{P}-30 \mathrm{~N}$ and general aviation multi-element aerofoils. Figure 5B illustrates the pressure coefficient distribution at 60 AOA computed for Mach number of 0.1 The lift produced on wing is affected by angle of attack distribution along the wing span. The gradient pressure recovery along the wing chord during ascent and descent conditions also serve to reduce aerodynamic pressure drag and allow the smoother air flow control over the wing surface. By reducing drag, the reduction in fuel consumption is achieved by average of $5 \%$ during such flight conditions. ${ }^{5}$ 


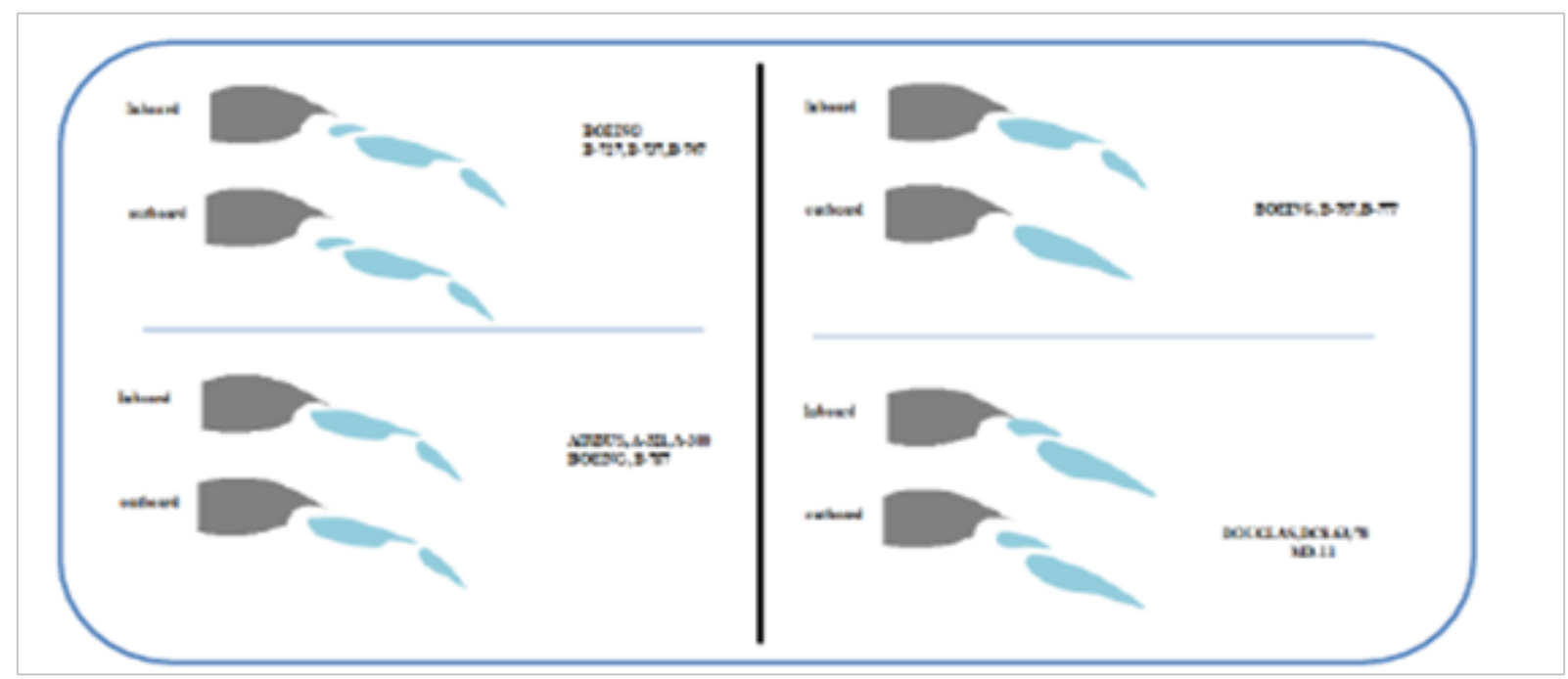

Figure 4 Schematic view of trailing edge flap/slat configurations used in Boeing, Airbus and Douglas aircrafts (adapted)., ${ }^{14}$
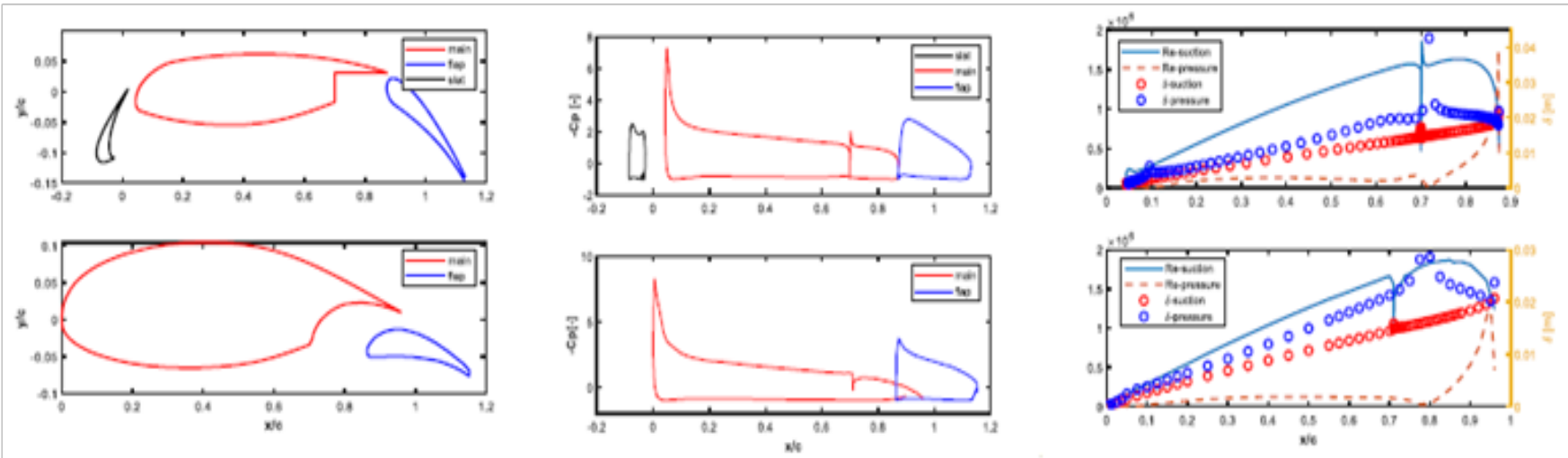

Figure 5 (A) Geometry of 30P-30N and GAW-I aerofoils (B) Pressure coefficient, Cp distribution using 2D viscous panel method for 30P-30N and GAW-I aerofoils at 60 angle of attack (AOA) and Reynolds number (Re) of $6.2 \times 105, \mathrm{M}-0.095$ (C) lllustration of chord Reynolds number and turbulent boundary layer thickness, $\delta$ in $\mathrm{m}$, on main element for $30 \mathrm{P}-30 \mathrm{~N}$ and GAW-I aerofoils at $60 \mathrm{AOA}$ using $2 \mathrm{D}$ viscous panel method.

\section{Conclusion}

Innovations in commercial passenger aircraft design are associated with application of interdisciplinary research in aerodynamic design methodologies, materials technology. Aerodynamics of morphed wing structures made from novel materials is giant step in improvement of the aircraft flight characteristics and provides impetus in aviation industry.

\section{Acknowledgment}

None.

\section{Conflicts of interest}

The authors declare that there is no conflict of interest.

\section{References}

1. https://www.grc.nasa.gov/www/k-12/airplane/flap.html

2. https://www.iata.org/publications/economics/fuel-monitor/Pages/index. aspx

3. https://www.theairlinepilots.com/forum/viewtopic.php?p=690

4. Daniel. R Aerodynamic design of airbus high-lift wings in a multidisciplinary environment. ECCOMAS. 2004.

5. Olivier Husse. Best practices for fuel economy, ICAO operational measures workshop, Montreal, 2006. 